\title{
Nitric Oxide Synthase Inhibitors
}

\author{
Elizabeth Igne Ferreira and \\ Ricardo Augusto Massarico Serafim
}

Additional information is available at the end of the chapter

http://dx.doi.org/10.5772/67027

\begin{abstract}
Nitric oxide (NO) is an endogenic product from plants, bacteria, and animal cells that has many important effects in those organisms. It is produced by nitric oxide synthase (NOS), which is found in main three isoforms, namely endothelial NOS (eNOS), inducible NOS (iNOS), and neuronal NOS (nNOS). It has an important role in homeostasis in different physiological systems, such as micro- and macro-vascularization, inhibition of platelet aggregation, and neurotransmission regulation in the central nervous, gastrointestinal, respiratory, and genitourinary systems. However, its overproduction has been associated with diseases such as arthritis, asthma, cerebral ischemia, Parkinson's disease, neurodegeneration, and seizures. For this reason, and due to better understanding of the molecular mechanisms by which NO provokes those diseases, the interest on the design of NOS inhibitors with therapeutic purposes has highly increased. Based on the foregoing considerations, the proposal of this chapter is to show an overview about the design strategies, mechanism of action at the molecular level, and the main advances toward the search for selective NOS inhibitors available in the literature.
\end{abstract}

Keywords: nitric oxide synthase isoforms, structure-based drug design, enzymatic inhibition, selectivity, heterocyclic compounds

\section{Introduction}

Nitric oxide (NO) is a diatomic neutral molecule, produced by bacteria, plants, and animals. Having one unpaired electron, its effect in biological system is related to the stabilization of this electron. It acts as dissolved nonelectrolyte in the organisms, except for the lungs, where it is found in gaseous state [1-3]. 
NO has gain importance mainly in the 1990s, and from then on, it has been studied to obtain interesting pharmacological effects. A review by Serafim and collaborators describes the state of the art of this compound use in drug design [4].

The basal NO production has an important contribution to homeostasis in different physiological systems, such as micro- and macro-vascularization, inhibition of platelet aggregation, and neurotransmission regulation in central nervous, gastrointestinal, respiratory, and genitourinary systems. However, $\mathrm{NO}$ overproduction has been strongly associated with some diseases such as arthritis, asthma, cerebral ischemia, Parkinson's disease, neurodegeneration, and seizures [5-9].

Nitric oxide synthase (NOS) is the enzyme responsible for NO biosynthesis, and there are three main kinds of NOS isoforms [endothelial NOS (eNOS), inducible NOS (iNOS), and neuronal NOS (nNOS)]. They are tetramers, constituted of two NOS monomers associated with two calmodulin monomers (CaM), and contain relatively tightly bound cofactors, $\mathrm{BH}_{4^{\prime}}$ FAD, FMN, and iron protoporphyrin IX (heme group). Their chemical function is to catalyze the reaction of L-arginine, NADPH, and oxygen to synthesize free radical NO, L-citrulline, and NADP (Figure 1) [10].

The substrate L-arginine establishes H-bond networks inside the catalytic site of NOS isoforms with the heme group, mainly due to the guanidine group, which is crucial to bind tightly using a salt-bridge interaction with the conserved carboxylate of Glu597 in human nNOS, Glu377 for iNOS and Glu361 for eNOS. In addition, L-arginine establishes H-bonds with the amide carbonyl from Trp592, in nNOS; with Trp372, in iNOS; and with Trp356, in eNOS. Moreover, $\alpha$-amino group of L-arginine interacts through $\mathrm{H}$-bond with the heme propionate side chain, and the guanidine $N$-terminal nitrogen of this amino acid coordinates with $\mathrm{Fe}^{\mathrm{II}}$ (Figure 2). This ligand-receptor interaction profile is similar to all isoforms, which generates a challenge to selectivity [11].

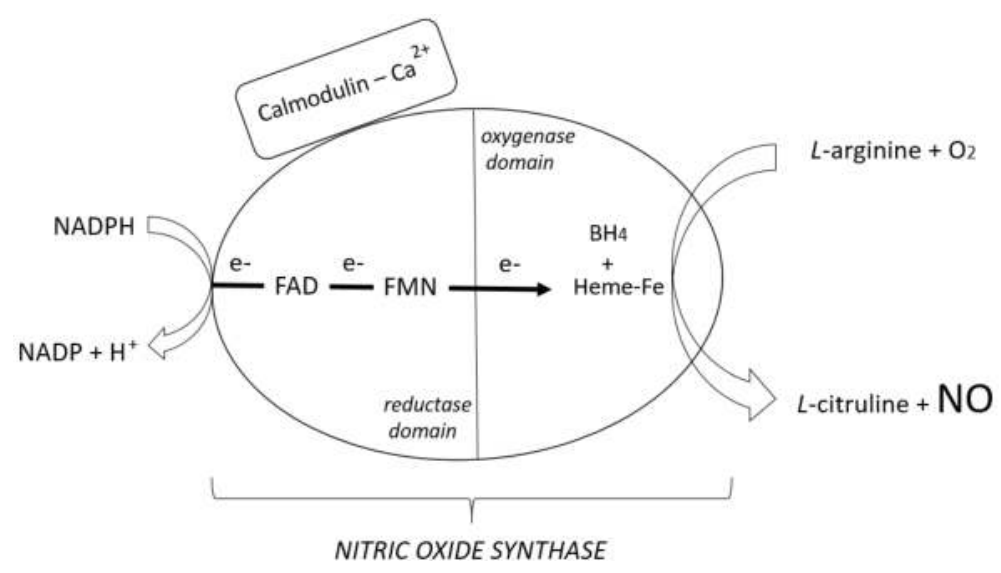

Figure 1. General reaction of NO formation by NOS. Adapted from [10]. 


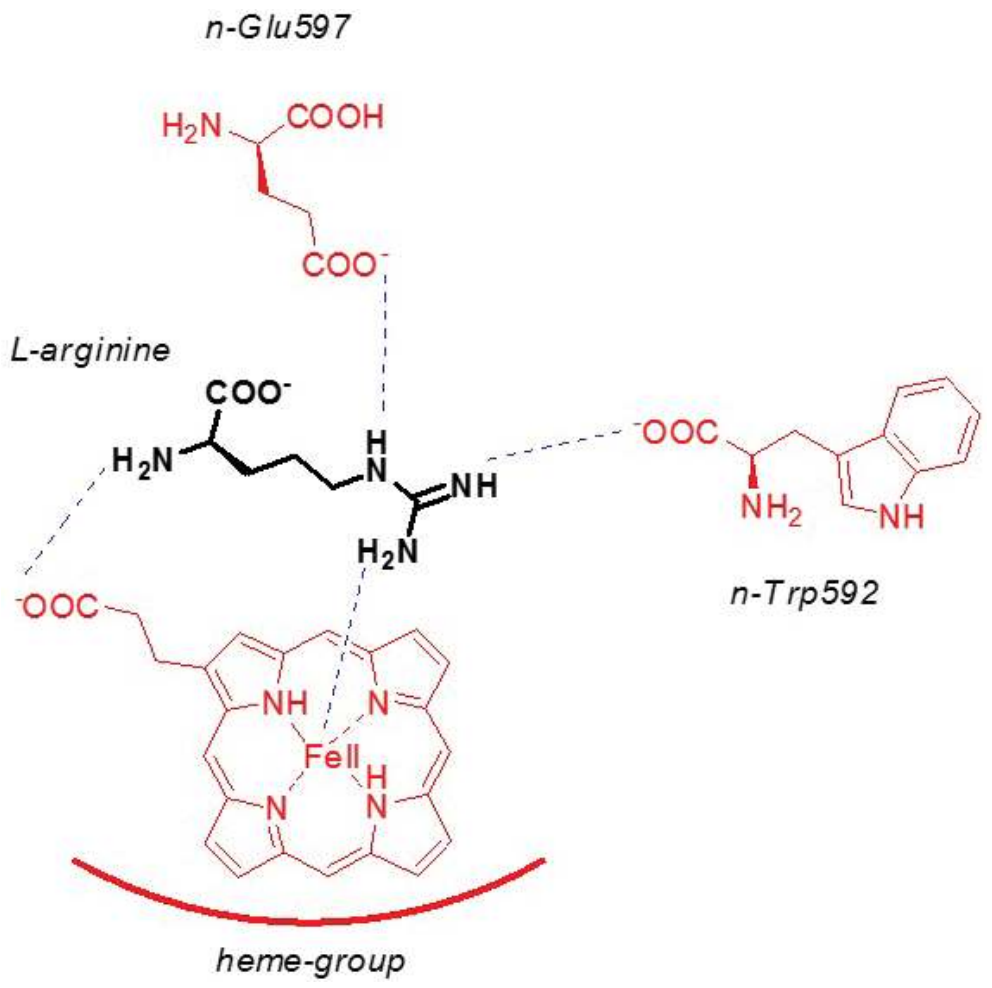

Figure 2. Scheme of nNOS-binding site.

Exacerbated induction of iNOS is associated with septic shock, inflammatory, and noninflammatory impairment processes in different tissues/organs, and, likewise, the nNOS is triggered in neurotoxicity, neurodegeneration process, and proliferation increase of some neoplastic cell lines. Depending on the clinical condition, decreasing NO levels is necessary, and excellent benefits might be achieved using NOS inhibitors. However, it is much important not to inhibit eNOS, because of its central role in smooth muscle relax, controlling vascular tone and blood pressure [12-14].

The first inhibitors designed (during the1980s and early 1990s) were based on L-arginine, the substrate of the enzyme, and this approach led to potent compounds but with poor selectivity level among the isoforms. In the late 1990s, the first crystal structure of iNOS and eNOS was unveiled, showing the high degree of similarity particularly in the active site of both isoforms. The nNOS crystal structure was reported in 2002, allowing the design of selective inhibitors $[15,16]$. It is worth noting that changes in some amino acids of the isoforms lead to differences in electronic and steric effects on the binding site region, which can be interesting for designing selective inhibitors [11, 15]. The active collaboration between Richard Silverman and Thomas Poulos' groups has significantly contributed to this field, and some of their papers are discussed in this chapter. 
NOS isoforms were validated as target for new drugs soon after their X-ray crystallography was available. From then on the design of effective and selective inhibitors has been an important approach in modern drug discovery involving NO biochemical pathways related to many dysfunctions of the human organism [12, 17-19].

\section{Experimental studies}

\subsection{Inducible nitric oxide synthase (iNOS) inhibitors}

Garvey and collaborators (1994) were the first to report highly selective iNOS inhibitors. The compounds were isothiourea derivatives (Figure 3-1) designed as L-arginine-competitive reversible inhibitors of human iNOS, with a $K_{\mathrm{i}}=47 \mathrm{nM}$ and a 190-fold selectivity over eNOS but only $\sim 5$-fold over nNOS $[10,20]$. Further studies of the group led to the design of compound 1400W (Figure 3), which is highly selective over eNOS and nNOS and able to penetrate into cells and tissues [10, 21].

The selective iNOS inhibition by aminoguanidine (Figure 3-AG) showed that NO can mediate the disruption of hematopoiesis during acute graft-versus-host disease (GVHD), also decreasing the endogenous bacterial infections in the spleen and liver in mice receiving the inhibitor [22]. The deleterious neuro-inflammation effects of iNOS/NO system stimulated by lipopolysaccharide (LPS) on learning and memory were evaluated in rats. Aminoguanidine decreases TNF $\alpha$ levels, oxidative stress indicators, and NO metabolites [23]. In addition, this compound seems to significantly relieve periapical inflammation in the canine teeth of cats and to reduce histological multiple organ damage in rats [24, 25].

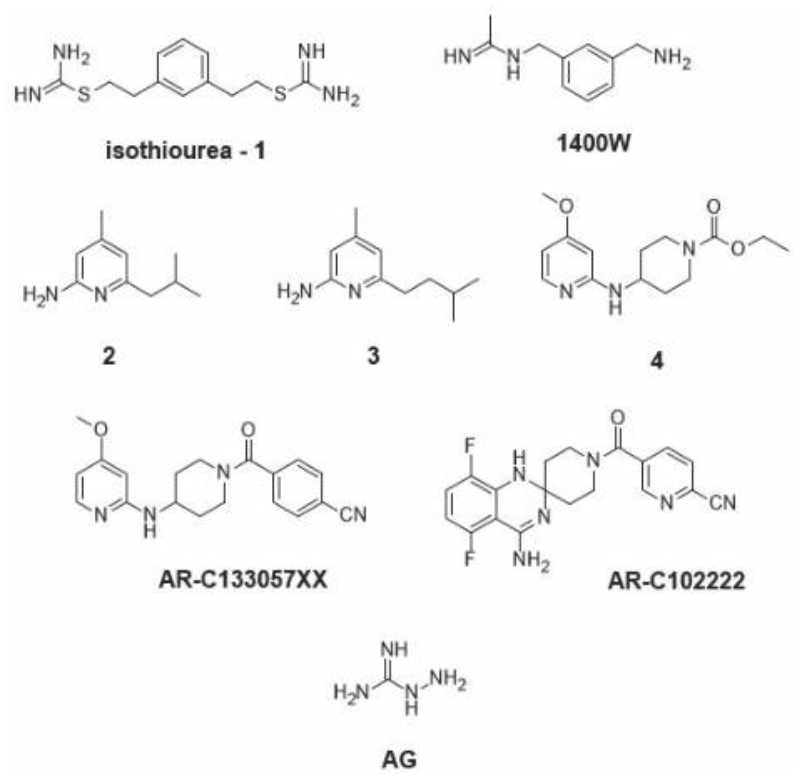

Figure 3. iNOS inhibitors (part 1). 
In 2000, Hagmann and collaborators explored the structure-activity relationships of a series of substituted 2-aminopyridines. Compounds 4,6-dialkyl substituted (Figure 3-2 and 3) were found to be the most potent inhibitors of iNOS, presenting a significant degree of selectivity for this isoform [26]. Exploring the same scaffold, the synthesis of the derivatives N-4-piperidinyl2-aminopyridine led to compound 4 (Figure 3), a 4-methoxy substituted derivative, 4-fold more potent in iNOS inhibition compared to the 4-methyl compound. Moreover, 4-cyanobenzamide derivative (Figure 3-AR-C133057XX) presented $\mathrm{IC}_{50}=0.071 \mu \mathrm{M}$, being 1400-fold and around 100-fold selective for eNOS and nNOS, respectively. X-ray crystallography of AR-C133057XX showed that pyridine moiety binds deeply to the heme pocket, while the exocyclic ring interacts with another binding pocket. This difference in interaction could explain the good selectivity of this molecule [27].

On the other hand, the 1,2-dihydro-4-quinazolinamine compound AR-C102222 (Figure 3) showed a dose-dependent inhibition on NO production induced by lipopolysaccharide (LPS). At the highest dose tested $(100 \mu \mathrm{mol} / \mathrm{kg})$ in rats, this compound completely abolished the chronic inflammatory arthritis development all over the 20-day experiment, thus confirming the in vivo efficacy of the class [28].

Structural-based approach using crystal structure and mutagenesis have identified specific induced-fit binding mode, which can generate some conformational changes toward a new specific cavity. Garcin and coworkers showed the cis-amidine moiety of quinazoline and aminopyridine chemotypes in the compounds AR-C133057XX and AR-C102222, respectively, promoted interactions of hydrogen with Glu (Glu371 and Glu377, mouse and human, respectively) at the binding site and with the heme group (mimicking the L-arginine substrate) (Figure 4). Those interactions increased the affinity of the inhibitor-containing bulky groups for iNOS. This occurs when Gln rotates on its own axis, accommodating the rigid bulky moieties of the inhibitors and exposing a new specific pocket to interact. The Gln-open conformation can create a cascade of conformational changes, leading to the generation of this new interaction site and directing the selectivity to the aminopyridine and quinazoline scaffolds [29]. Quantitative structure-activity relationships (QSAR) of quinazoline derivatives have been performed to evaluate the structural features required to interact with the active site of iNOS, allowing the design of more effective inhibitors [30].

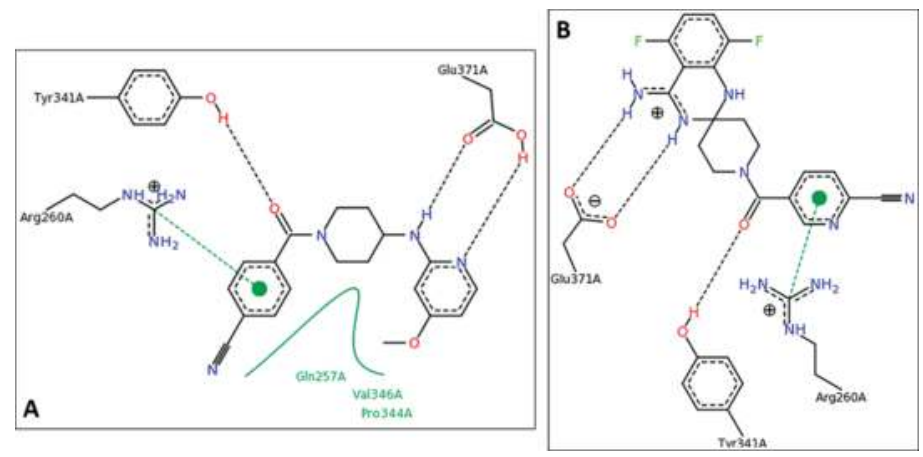

Figure 4. (A) iNOS-binding profile of AR-C133057XX, PDB code: 3EAI; (B) iNOS-binding profile of AR-C102222, PDB code: 3E7T. 
Other compounds, as acetamidine derivatives (Figure 5-5 and 6), designed to inhibit iNOS, showed submicromolar activities $\left(\mathrm{IC}_{50}=0.428\right.$ and $0.165 \mu \mathrm{M}$, respectively) and excellent selectivity over eNOS (>2300 and 550-fold more selective, respectively). In silico findings revealed that the activity drastically changes when ending amino groups are located instead of carboxylic function in the acceptor H-bond region, which is adjacent to the lipophilic region. This occurs because the charged amino group and its alkyl chain are not able to be stabilized inside the pocket interaction region of the enzyme, decreasing the binding efficiency [31].

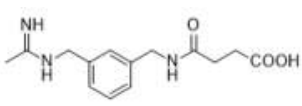

5

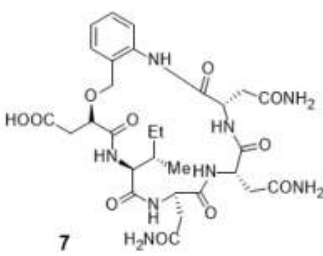

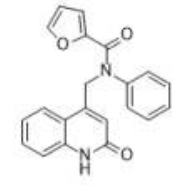

8

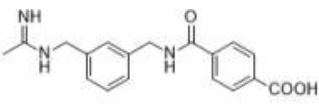

6
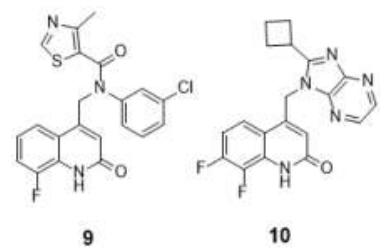

10

Figure 5. iNOS inhibitors (part 2).

A protein called SPSB2 plays an important role in modulating the activity of iNOS through its proteasomal degradation in defense cells. Since this complex is blocked, the NO production from iNOS is prolonged, increasing the killing activity against pathogen microorganisms, making it an interesting anti-infective target [32]. Some cyclic peptidomimetic compounds were designed using this strategy, and the most potent compound 7 (Figure 5) showed strong inhibition of SPSB2-iNOS complex in macrophage cell lysates and potent affinity value $\left(K_{D}=29 \mathrm{nM}\right)[33]$.

High-throughput screening (HTS) strategy has been used to identify new iNOS inhibitors hits such as the compound 8 (Figure 5). After structural optimization process, the quinolone amide derivative 9 (Figure 5) was generated. This derivative has 2000-fold selectivity over human eNOS, besides being very potent (iNOS $\mathrm{IC}_{50}=11 \mathrm{nM}$ ) and presenting oral bioavailability in mouse although its clearance $(\mathrm{Clp}>100 \mathrm{~mL} / \mathrm{min} / \mathrm{kg}$ ) has shown to be uninteresting [34]. The efforts to overcome this effect was to improve the pharmacokinetic properties, leading to the compound 10 (Figure 5), a 4,7-imidazopyrazine derivative. This is a dual iNOS/nNOS inhibitor, showing high potency in human iNOS $\left(\mathrm{IC}_{50}=0.091 \mu \mathrm{M}\right)$ and activity over nNOS $(0.30 \mu \mathrm{M})$ while maintaining the desired selectivity over eNOS (180-fold). Its mechanism of action at molecular level is based on the inhibition of the iNOS dimerization process. Furthermore, compound 10 was effective using in vivo models of neuropathic pain, presenting desired clearance value (4-9 $\mathrm{mL} / \mathrm{min} / \mathrm{kg})$, good oral bioavailability, and no tolerance after repeated doses [35].

Phenylpyrroles, pyrazoles, urea kynurenamines, ethynylcyanodienones, and amidine derivatives (Figure 6-11, 12, 13, 14, and 15) have also been interesting scaffolds to generate iNOS inhibitors [36-40]. The first derivative reduced significantly the iNOS activity to control 
values in MPTP-Parkinson's disease model, showing a potential to act in central nervous system (CNS) disorders [36].<smiles>CNC(=O)c1ccc(-c2ccccc2N)[nH]1</smiles>

11<smiles>C#CC1(C)C=CC(=O)C(C#N)=C1</smiles>

14<smiles>Oc1ccc(/C=C/c2cc(-c3ccccc3)n[nH]2)cc1F</smiles>

12<smiles>CC(C)CC(=N)NCCCC(N)C(=O)O</smiles>

15<smiles>CCNC(=O)NCCC(=O)c1cc(Cl)ccc1N</smiles>

13

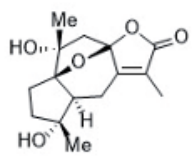

16

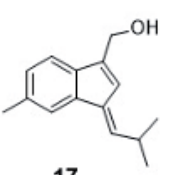

17

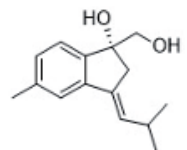

18

Figure 6. iNOS inhibitors (part 3).

Natural products have been a rich source of new bioactive molecules. Some examples in the NOS inhibition are a sesquiterpenoid, isolated from Curcuma wenyujin (Figure 6-16) and its isomer. They were strong inhibitors of NO production by LPS in iNOS $\left(\mathrm{IC}_{50}=7.6\right.$ and $8.5 \mu \mathrm{M}$, respectively). Anmindenols A and B (Figure 6-17 and 18), from marine-derived bacterium Streptomyces sp., also demonstrated a relevant inhibitory activity in macrophage cells NO production ( $\mathrm{IC}_{50}=23$ and $19 \mu \mathrm{M}$, respectively) [41, 42].

\subsection{Neuronal nitric oxide synthase (nNOS) inhibitors}

In the beginning of the 1990s, efforts to design selective nNOS inhibitor compounds were addressed, using the substrate L-arginine as the prototype molecule. Series of analogs was synthesized to evaluate which molecular change could interfere in the ligand activity and selectivity over other isoforms. The first selective compound over nNOS was L-nitroarginine (Figure 7), producing hypertension in animals due to the lack of selectivity over eNOS. In addition, many peptide analogs were synthesized trying to obtain more promising compounds. After the X-ray crystal complex elucidation, structure-activity relationship findings of several scaffolds have been explored to identify the molecular basis of improving the selectivity toward neuronal isoform $[15,19]$.

The non-arginine-based compound 7-nitroindazole (Figure 7-NI) showed little nNOS in vitro selectivity but high in vivo selectivity. Its mechanism of action involves competitive inhibition of $\mathrm{H}_{4} \mathrm{~B}$ cofactor, and series of related structures have been designed [11]. This compound has suppressed open-field behavior expressed as distance moved, exploratory rearing and grooming, suggesting that this compound can increase cortical excitability and interfere with some physiological and behavioral parameters [43]. Nevertheless, its anticonvulsant activity 
should be better understood, since studies in rodents reveal a beneficial activity although proconvulsant effect can be found in kainite-, nicotine- and soman-induced convulsions [44].

Entrena and collaborators, by using kynurenamine scaffold (Figure 7-19) as a template, carried out the synthesis of a series of new candidates to neuroprotective compounds, showing a pharmacophore model to interact with nNOS catalytic site [45].<smiles>N=C(NCCCC(N)C(=O)O)NNC(=O)[O-]</smiles>

L-nitroarginine

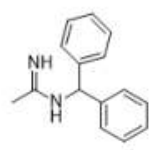

21

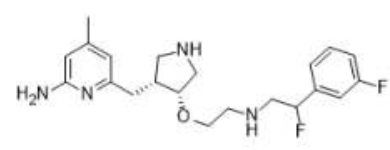

23<smiles>COc1ccc(N)c(C(=O)CCNC(C)=O)c1</smiles>

19<smiles>CC(=N)NC(c1ccccc1)C(C)C</smiles>

20

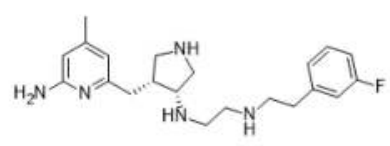

22

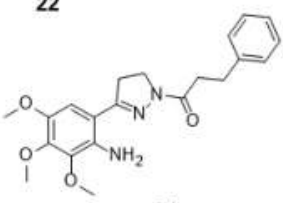

24<smiles>O=[N+]([O-])c1cccc2cn[nH]c12</smiles>

Figure 7. nNOS inhibitors (part 1).

$N$-Substituted acetamidines (Figure 7-20 and 21) showed nNOS inhibition activity $\left(\mathrm{IC}_{50}=0.2\right.$ and $0.3 \mu \mathrm{M}$ ) with good selectivity index (500 and 1166-fold selectivity over eNOS, respectively, and 50 and 100-fold, over iNOS, respectively). In silico studies were useful to understand the fit of these scaffolds inside the catalytic site. nNOS contains a bigger heme group cavity compared with other isoforms, which could explain why bulky groups better accommodate in the neuronal isoform [46].

Aminopyridine is an attractive pharmacophoric group to bind in different regions of nNOS through H-bond. Using this moiety, compound 22 (Figure 7) and its optical isomer showed to be selective against nNOS, although unable to penetrate the blood-brain-barrier (BBB) in in vivo studies $[15,47,48]$. Trying to increase the CNS permeability, prodrug design approach was used in primary and secondary amines. However, this strategy did not increase the BBB penetration, even masking the charge by carbamate and azide functions [49]. On the other hand, using these compounds containing basic nitrogen, Xue and coworkers attached electron-withdrawing groups (Figure 7-23) close to these amine functions, decreasing their $\mathrm{pKa}$ values and improving the membrane permeability in cell-based assays [50].

Concerning 4,5-dihydro-1- $\mathrm{H}$-pyrazole derivatives, they were confirmed as selective nNOS inhibitors. Compound 24 (Figure 7), the most active of the derivatives (82\% of inhibition), 
showed that its methoxy electron-donating group is important to improve potency and selectivity. By molecular modeling, it was possible to identify that the phenyl moiety can fit below the heme group, establishing $\pi-\pi$ interaction. The methoxy groups adopt a conformation that allows them to interact with Arg481 by H-bonds. Moreover, the amine group interacts by $\mathrm{H}$-bond with one of the carboxylate moieties of the heme group. On the contrary, electronwithdrawing groups are better to generate inhibitors for iNOS [51].

Other interesting structures such as 2-aminoquinolines are effective scaffold to be included in the structure of nNOS inhibitors. Crystallography studies showed that those compounds act as competitive arginine mimics. This scaffold makes important H-bonds with the activesite Glu residue, and the non-coordinating aryl rings are stabilized in a hydrophobic pocket in the extremity of the substrate access channel. Moreover, this structural class showed good pharmacokinetic properties (Figure 8-25), such as brain penetration and oral bioavailability according to the permeability results in Caco-2 cell assay [52]. Trying to optimize this class of compounds, chlorine was added on the phenyl ether central aryl ring (Figure 8-26). This substitution was found to be selective and highly potent in the design of nNOS inhibitors while retaining CNS penetration and showing a diminished off-target interaction. In complex with human nNOS, this compound showed a phenyl ring orientation where the alkyl amine makes an $\mathrm{H}$-bond with the $\mathrm{H}_{4} \mathrm{~B}$ site [53].

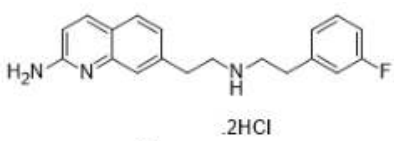

25

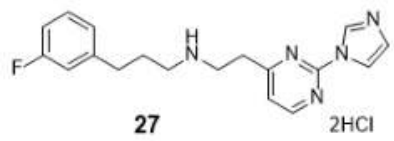<smiles>CNCc1cc(OCc2ccc3ccc(N)nc3c2)ccc1Cl</smiles>

26<smiles>Cc1cc(N)nc(CCc2cncc(CCCN(C)C)c2)c1</smiles>

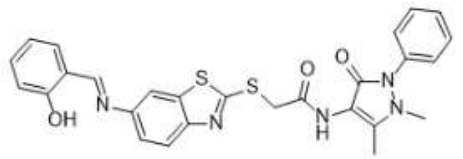

29

Figure 8. nNOS inhibitors (part 2).

Exploring the heme-coordinating potential of imidazole group, a series of 2,4-disubtituted pyrimidine compounds (Figure 8-27) was designed. They presented a nanomolar affinity to both rat and human nNOS ( $>200$-fold and $>100$-fold selectivity over eNOS and iNOS, respectively), exhibiting a minimal off-target binding to $50 \mathrm{CNS}$ receptors. Crystal structures of the complex (nNOS-27) indicate that heme Fe coordinates by the 2-imidazolyl group, and the non-coordinating aryl rings are stabilized in a hydrophobic pocket at the far end of the substrate access channel. The fluorine atom in compound 27 also interacts into the hydrophobic 
pocket, and the secondary amine of this derivative establishes dual ionic interaction with both heme propionates (Figure 9). This molecular interaction profile is important to obtain potency and selectivity. In addition, nitrogen from pyrimidine ring performs an H-bond with the His342 side chain. The imidazole ring of the most active compound acts as a weak CYP3A4 inhibitor, suggesting that modulating hydrophobicity and bulkiness can be useful to attenuate the effects in CYP isoforms [54].

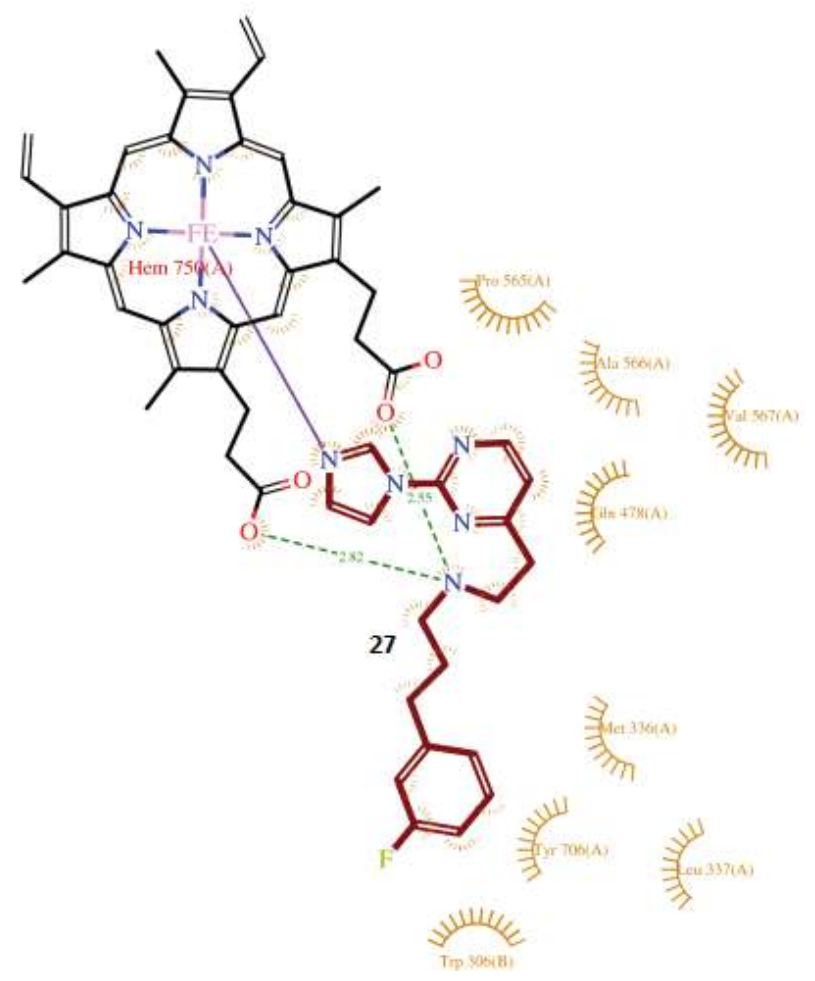

Figure 9. Rat nNOS-binding profile of $27, P D B$ code: $4 \mathrm{~V} 3 \mathrm{X}$.

Studies using aminopyridine-based scaffold with pyridine linker (Figure 8-28) showed that difference in the position of an amino acid, Asp597 of nNOS versus Asn368 of eNOS, controls the affinity and binding mode of this class of nNOS inhibitors. While the central pyridine is at least partially protonated to points up toward Tyr562 for optimal electrostatic interactions, the Asp597 provides additional and important electrostatic stabilization to the other part of the inhibitor [55-57].

Rational strategy for identifying new nNOS inhibitors using a combination of virtual screening approach based on 3D pharmacophore model and molecular docking was able to identify a hit compound structurally different from the available inhibitors (Figure 8-29). This strategy can be useful to design novel optimized analogs [58]. 


\subsubsection{Double-headed nNOS inhibitors}

Double-headed compounds have been explored by researches with the aim of obtaining high affinity binding in nNOS. Attaching a double-headed aminopyridine moiety in a compound led to a very potent $\left(K_{i}=25 \mathrm{nM}\right)$ and selective (107-fold selective over nNOS and eNOS) compound (Figure 10-30). Both aminopyridine moieties interact in different positions with the enzyme-Glu592 in the active site and the heme group. According to the X-ray crystals, there is a second $\mathbf{3 0}$ molecule binding also in the $\mathrm{H}_{4} \mathrm{~B}$ site, specifically, and the pyridine moiety coordinates with the $\mathrm{Zn}$ atom. This interaction does not take place in eNOS. Cellular permeability studies confirmed compound $\mathbf{3 0}$ as an interesting lead [59,60].

Other symmetric double-headed aminopyridine series without charge groups were designed to contain a tail on the central aromatic ring. The objective is to achieve an interaction in the electronegative region in the catalytic site, since only the neuronal isoform has Asp597 in this region. Derivative 31 (Figure 10) was very potent $\left(K_{i}=56 \mathrm{nM}\right)$ and highly selective over other isoforms (472-fold selective for eNOS and 239-fold for iNOS). This occurs because an electropositive functional group (Ciano group) is preferred near Asp597 in nNOS, explaining the selectivity of this compound [61].

Furthermore, double-headed inhibitors containing chiral linkers derived from natural amino acids were designed and synthesized. The best compound (Figure 10-32) showed high potency $\left(K_{i}=32 \mathrm{nM}\right)$ against nNOS and a good selectivity profile (475-fold selective and 244-fold over eNOS and iNOS, respectively). The aminomethyl moiety was crucial in this compound, allowing it to bind to the heme propionates in nNOS and leading to a high selectivity level [62].

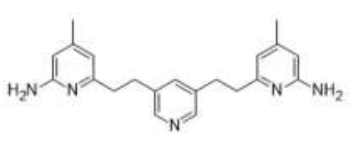

30

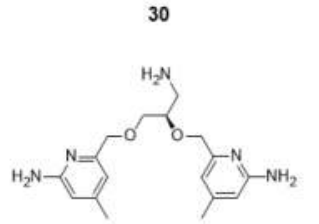

32

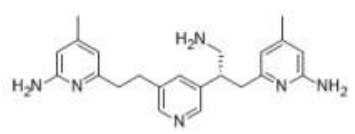

34

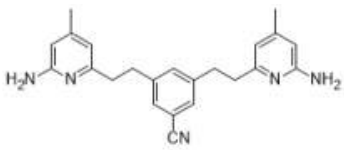

31

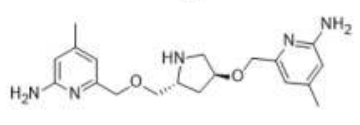

33

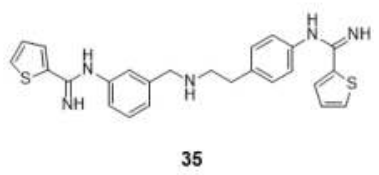

Figure 10. Double-headed nNOS inhibitors.

2-Amino-4-methylpyridine groups with a chiral linker derived from proline were designed as selective nNOS inhibitors. They showed to be interesting as they can interact in a unique orientation, what led to selectivity toward neuronal isoform. The aminopyridine groups 
interact with a Glu592 residue and the heme propionate in nNOS active site. In addition, the nitrogen from pyrrolidine linker is important to contribute to additional hydrogen bonds to the heme propionate, resulting in the most potent compound $\left(K_{i}=9.7 \mathrm{nM}\right)$ (Figure 10-33). The finding that the isomer activities are different also reinforces the importance of chirality control of this kind of inhibitors and shows the dynamism of the target [63].

In addition, using chiral double-headed inhibitors, the $\alpha$-amino-functionalized aminopyridine derivative 34 (Figure 10) was more potent than other chiral compounds $\left(K_{i}\right.$ value of 24 $\mathrm{nM}$ for nNOS, with 273-fold and 2822-fold selectivity against iNOS and eNOS, respectively). Structure-activity relationship studies reveal that the $\alpha$-amino group close to the center phenyl ring is crucial to stabilize the double-headed binding. Those studies also showed that by changing to aminomethyl group the potency is improved. The inhibitor is able to make $\mathrm{H}$-bonds with both the $\mathrm{H}_{4} \mathrm{~B}$ binding site and the propionate of the heme A-ring, which is essential to obtain selectivity over other isoforms. It is also important to note that the distinct electrostatic environments in different isoforms resulted in lower binding free energy in nNOS, which also can explain the potency difference [64].

The non-chiral double-headed thiophene-2-carboximidamide compound (Figure 10-35) exhibited an excellent inhibitory potency and selectivity $\left(K_{i}=5 \mathrm{nM}\right.$; 540-fold and 340-fold selective over eNOS and iNOS, respectively). This compound also showed to be active in metastatic melanoma A375 cells, exhibiting $\mathrm{EC}_{50}$ values of $1.3 \mu \mathrm{M}$, better that of the drug cisplatin $\left(\mathrm{EC}_{50}=4.2 \mu \mathrm{M}\right)[65]$.

\subsection{Bacterial nitric oxide synthase (bNOS) inhibitors}

Bacterial nitric oxide synthase (bNOS) is present in many Gram-positive microorganisms and has been described as part of their defense system against other species and the oxidative stress provoked by antibiotics through NO releasing. Therefore, bNOS inhibition can increase the antibiotic potential and be harmful to bacterial cell [66].

A screening showed that some known nNOS inhibitors can decrease significantly the percent survival of Bacillus subtilis WT treated with the antimicrobial acriflavine. This potential is consistent with NO production inhibition, as it decreases the bacterial resistance against that compound [67].

Exploring the potential of bNOS as a drug target, high selectivity levels are necessary to its inhibitors. In this context, the design of compounds that target the active and pterin-binding site has been considered an important strategy (Figure 11-36). These compounds are able to carry out an unexpected rotameric position of residue Arg247 in the active site, besides interacting with the important residue of Glu243 from the same site [68].

In addition, with the goal to identify the differences among bNOS and other isoforms, crystallography studies were performed using different inhibitor chemotypes. Researchers observed that Tyr706 from nNOS is conserved in bNOS (Tyr 357) and both have the same rotameric behavior, which is very different, compared with eNOS. This molecular feature can be useful to design new selective bNOS over eNOS inhibitor. Since the pharmacokinetic properties are very different between $\mathrm{bNOS}$ and nNOS, selectivity over the latter is not a trouble. However, 
due to steric hindrance in the tail end of thiophenecarboximidamide analogs, this scaffold can bind differently to bNOS comparatively to nNOS [69].<smiles>N=C(Nc1cccc(OCC(O)c2cccc(NC(=N)c3cccs3)c2)c1)c1cccs1</smiles>

Figure 11. bNOS inhibitor.

\section{Clinical studies}

A nonselective compound L-NMMA (Figure 12), also known as tilarginine, was evaluated clinically in Translational Research Investigating Underlying Disparities in Acute Myocardial Infarction Patients' Health Status (TRIUMPH) study in North America and Europe with planned enrollment of 658 patients at 130 centers. The period of study was between January 2005 and August 2006 (the study was terminated early). Using $1 \mathrm{mg} / \mathrm{kg}$ bolus and $5 \mathrm{~h}$ infusion did not decrease the mortality rates in patients with refractory cardiogenic shock complicating myocardial infarction despite an open infarct artery. Although the good results showed in phase II, it has failed in phase III [70, 71]. In another study L-NMMA resulted in no differences in mean arterial pressure (MAP) after $2 \mathrm{~h}$ compared with placebo group [72].

Evaluating another inhibitor, N(G)-nitro-L-arginine methyl ester (Figure 12-L-NAME), in the treatment of refractory cardiogenic shock, the death at 1 month was $27 \%$ in the L-NAME group versus $67 \%$ in the control group [73]. Additional studies have been performed to further examination, concluding that TRIUMPH strongly indicated that nonselective NOS inhibitors are not clinically interesting [74].<smiles>CNC(=N)NCCCC(N)C(=O)O</smiles>

L-NMMA<smiles>COC(=O)C(N)CCCNC(=N)N[N+](=O)[O-]</smiles>

L-NAME<smiles>O=C(/C=C/c1ccc(Cl)cc1)NC(Cc1ccccn1)C(=O)NCC(=O)N1CCC(Oc2cc(C(F)(F)F)ncn2)CC1</smiles>

ASP9853

Figure 12. Clinically evaluated compounds. 
Recent phase I study in advanced solid tumors with the iNOS inhibitor ASP9853 (Figure 12) showed that the efficacy dose predicted in preclinical studies was not achieved due to overall toxicity limitations. In summary all these clinical information showed that the manipulation of the NOS pathway, with or without chemotherapy, appears to be more challenging than expected [75]. While designing new selective NOS inhibitors which should be highlighted, deeply studies to evaluate clinical benefits are also required.

\section{Conclusions}

Many scaffolds have been found to inhibit nitric oxide synthases. Some of them were presented in this chapter as promising for important therapeutic activity. It must be emphasized that the research about nitric oxide synthase inhibitors has expressively advanced thanks to the X-ray crystallographic studies of this enzyme. This helps the structure-based design approach toward the search for selective inhibitors of this enzyme and the comprehension of their mechanism of action. Notwithstanding, efforts have been made for imparting them with a drug-like profile.

\section{Ackowledgements}

The authors thank CAPES, for RAM Serafim scholarship, and CNPq, for EI Ferreira fellowship.

\section{Author details}

Elizabeth Igne Ferreira* and Ricardo Augusto Massarico Serafim

*Address all correspondence to: elizabeth.igne@gmail.com

LAPEN, Department of Pharmacy, Faculty of Pharmaceutical Sciences, University of Sao Paulo - FCF/USP, Sao Paulo, Brazil

\section{References}

[1] Kerwin JF, Lancaster JR, Feldman PL. Nitric oxide: a new paradigm for second messengers. Journal of Medicinal Chemistry. 1995;38:4343-4362. DOI: 10.1021/jm00022a001

[2] Al-sadoni HH, Ferro A. S-nitrosothiols: a class of nitric oxide-donor drugs. Clinical Science. 2000;98:507-520. DOI: 10.1042/cs0980507

[3] Daff S. NO synthase: structures and mechanisms. Nitric Oxide. 2010;23:1-11. DOI: 10.1016/j.niox.2010.03.001

[4] Serafim RAM, Primi MC, Trossini GHG, Ferreira EI. Nitric oxide: state of the art in drug design. Current Medicinal Chemistry. 2012;19:386-405.DOI:10.2174/092986712803414321 
[5] Hobbs AJ, Higgs A, Moncada S. Inhibition of nitric oxide synthase as a potential therapeutic target. Annual Review of Pharmacology and Toxicology. 1999;39:191-220. DOI: 10.1146/annurev.pharmtox.39.1.191

[6] Rehni AK, Singh TG, Kalra R, Singh N. Pharmacological inhibition of inducible nitric oxide synthase attenuates the development of seizure in mice. Nitric Oxide. 2009;21: 120-125. DOI: 10.1016/j.niox.2009.06.001

[7] Kavya R, Saluja R, Singh S, Dikshit M. Nitric oxide synthase regulation and diversity: implications in Parkinson's disease. Nitric Oxide. 2006;15:280-294. DOI: 10.1016/j. niox.2006.07.003

[8] Zheng B, Zheng T, Wang L, Chen X, Shi C, Zhao S. Aminoguanidine inhibition of iNOS activity ameliorates cerebral vasospasm after subarachnoid hemorrhage in rabbits via restoration of dysfunctional endothelial cells. Journal of the Neurological Sciences. 2010;295:97-103. DOI: 10.1016/j.jns.2010.04.012

[9] Ricciardolo FLM, Nijkamp FP, Folkerts G. Nitric oxide synthase (NOS) as therapeutic target for asthma and chronic obstructive pulmonary disease. Current Drug Targets. 2006;7:721-735. DOI: 10.2174/138945006777435290

[10] Alderton WK, Cooper CE, Knowles RG. Nitric oxide synthases: structure, function and inhibition. Biochemical Journal. 2001;357:593-615. DOI: 10.1042/bj3570593

[11] Mukherjee P, Cinelli MA, Kang S, Silverman RB. Development of nitric oxide synthase inhibitors for neurodegeneration and neuropathic pain. Chemical Society Reviews. 2014;43:6814-6838. DOI: 10.1039/c3cs60467e

[12] Vallance P, Leiper J. Blocking NO synthesis: how, where and why? Nature Review Drug Discovery. 2002;1:939-950. DOI: 10.1038/nrd960

[13] Vallance, P. Nitric oxide: therapeutic opportunities. Fundamental and Clinical Pharmacology. 2003;17:1-10. DOI: 10.1046/j.1472-8206.2003.00124.x

[14] Yang Z, Misner B, Ji H, Poulos TL, Silverman RB, Meyskens FL, Yang S. Targeting nitric oxide signaling with $\mathrm{nNOS}$ inhibitors as a novel strategy for the therapy and prevention of human melanoma. Antioxidants and Redox Signaling. 2013;19:433-447. DOI: 10.1089/ ars. 2012.4563

[15] Silverman RB. Design of selective neuronal nitric oxide synthase inhibitors for the prevention and treatment of neurodegenerative diseases. Accounts of Chemical Research. 2009;42:439-451. DOI: 10.1021/ar800201v

[16] Annedi SC. Cell-permeable inhibitors of neuronal nitric oxide synthase open new prospects for the treatment of neurological disorders. Journal of Medicinal Chemistry. 2015;58:1064-1066. DOI: 10.1021/acs.jmedchem.5b00057

[17] Paige J, Jaffrey SR. Pharmacologic manipulation of nitric oxide signaling: targeting NOS dimerization and protein-protein interactions. Current Topics in Medicinal Chemistry. 2007;7:97-114. DOI: 10.2174/156802607779318253 
[18] Groves JT, Wang CCY. Nitric oxide synthase: models and mechanism. Current Opinion in Chemical Biology. 2000;4:687-695. DOI: 10.1016/S1367-5931(00)00146-0

[19] Poulos TL, Li H. Structural basis for isoform-selective inhibition in nitric oxide synthase. Accounts of Chemical Research. 2013;46:390-398. DOI: 10.1021/ar300175n

[20] Garvey EP, Oplinger JA, Tanoury GJ, Sherman PA, Fowler M, Marshall S, Harmon MF, Paith JE, Furfine ES. Potent and selective inhibition of human nitric oxide synthases. Inhibition by non-amino acid isothioureas. The Journal of Biological Chemistry. 1994;269:26669-26676.

[21] Garvey EP, Oplinger JA, Furfine ES, Kiff RJ, Laszlo F, Whittle BJ, Knowles RG. 1400W is a slow, tight binding, and highly selective inhibitor of inducible nitric oxide synthase in vitro and in vivo. The Journal of Biological Chemistry. 1997;272:4959-4963.

[22] Hoffman RA, Nussler NC, Gleixner SL, Zhang G, Ford HR, Langrehr JM, Demetris AJ, Simmons RL. Attenuation of lethal graft-versus-host disease by inhibition of nitric oxide synthase. Transplantation. 1997;63:94-100.

[23] Anaeigoudari A, Soukhtanloo M, Reisi P, Beheshti F, Hosseini M. Inducible nitric oxide inhibitor aminoguanidine, ameliorates deleterious effects of lipopolysaccharide on memory and long term potentiation in rat. Life Sciences. 2016;158:22-30. DOI: 10.1016/j.lfs.2016.06.019

[24] Farhad AR, Razavi S, Jahadi S, Saatchi M. Use of aminoguanidine, a selective inducible nitric oxide synthase inhibitor, to evaluate the role of nitric oxide in periapical inflammation. Journal of Oral Science. 2011;53:225-230.

[25] Soliman MM. Effects of aminoguanidine, a potent nitric oxide synthase inhibitor, on myocardial and organ structure in a rat model of hemorrhagic shock. Journal of Emergencies, Trauma and Shock. 2014;7:190-195. DOI: 10.4103/0974-2700.136864

[26] Hagmann WK, Caldwell CG, Chen PL, Durette PL, Esser CK, Lanza TJ, Kopka IE, Guthikonda R, Shah SK, Maccoss M, Chabin RM, Fletcher D, Grant SK, Green BG, Humes JL, Kelly TM, Luell S, Meurer R, Moore V, Pacholok SG, Pavia T, Williams HR, Wong KK. Substituted 2-aminopyridines as inhibitors of nitric oxide synthases. Bioorganic and Medicinal Chemistry. 2000;10:1975-1978. DOI: 10.1016/S0960-894X(00)00389-9

[27] Connolly S, Aberg A, Arvai A, Beaton HG, Cheshire DR, Cook AR, Cooper S, Cox D, Hamley P, Mallinder P, Millichip I, Nicholls DJ, Rosenfeld RJ, St-Gallay SA, Tainer J, Tinker AC, Wallace AV. 2-aminopyridines as highly selective inducible nitric oxide synthase inhibitors. Differential binding modes dependent on nitrogen substitution. Journal of Medicinal Chemistry. 2004;47:3320-3323. DOI: 10.1021/jm031035n

[28] Tinker AC, Beaton HG, Boughton-Smith N, Cook TR, Cooper SL, Fraser-Rae L, Hallam K, Hamley P, Mcinally T, Nicholls DJ, Pimm AD, Wallace AV. 1,2-Dihydro4-quinazolinamines: potent, highly selective inhibitors of inducible nitric oxide synthase which show antiinflammatory activity in vivo. Journal of Medicinal Chemistry. 2003;46:913-916. DOI: 10.1021/jm0255926 
[29] Garcin ED, Arvai AS, Rosenfeld RJ, Kroeger MD, Crane BR, Andersson G, Andrews G, Hamley PJ, Mallinder PR, Nicholls DJ, St-Gallay SA, Tinker AC, Gensmantel NP, Mete A, Cheshire DR, Connolly S, Stuehr DJ, Aberg A, Wallace AV, Tainer JA, Getzoff ED. Anchored plasticity opens doors for selective inhibitor design in nitric oxide synthase. Nature Chemical Biology. 2008;4:700-707. DOI: 10.1038/nchembio.115

[30] Sharma MC, Sharma S. Investigation on quantitative structure activity relationships of a series of inducible nitric oxide. Interdisciplinary Sciences. DOI: 10.1007/s12539-016-0176-5

[31] Maccallini C, Montagnani M, Paciotti R, Ammazzalorso A, De Filippis B, Di Matteo M, Di Silvestre S, Fantacuzzi M, Giampietro L, Potenza MA, Re N, Pandolfi A, Amoroso R. Selective acetamidine-based nitric oxide synthase inhibitors: synthesis, docking, and biological studies. ACS Medicinal Chemistry Letters. 2015;6:635-640. DOI: 10.1021/acsmedchemlett.5b00149

[32] Yap BK, Harjani JR, Leung EW, Nicholson SE, Scanlon MJ, Chalmers DK, Thompson PE, Baell JB, Norton RS. Redox-stable cyclic peptide inhibitors of the SPSB2-iNOS interactions. FEBS Letters. 2016;590:696-704. DOI: 10.1002/1873-3468.12115

[33] Harjani JR, Yap BK, Leung EWW, Lucke A, Nicholson SE, Scanlon MJ, Chalmers DK, Thompson PE, Norton RS, Baell JB. Design, synthesis, and characterization of cyclic peptidomimetics of the inducible nitric oxide synthase binding epitope that disrupt the protein-protein interaction involving SPRY domain-containing suppressor of cytokine signaling box protein (SPSB) 2 and inducible nitric oxide synthase. Journal of Medicinal Chemistry. 2016;59: 5799-5809. DOI: 10.1021/acs.jmedchem.6b00386

[34] Bonnefous C, Payne JE, Roppe J, Zhuang H, Chen X, Symons KT, Nguyen PM, Sablad M, Rozenkrants N, Zhang Y, Wang L, Severance D, Walsh JP, Yazdani N, Shiau AK, Noble SA, Rix P, Rao TS, Hassig CA, Smith ND. Discovery of inducible nitric oxide synthase (iNOS) inhibitor development candidate KD7332, part 1: identification of a novel, potent, and selective series of quinolinone iNOS dimerization inhibitors that are orally active in rodent pain models. Journal of Medicinal Chemistry. 2009;52:3047-3062. DOI: 10.1021/jm900173b

[35] Payne JE, Bonnefous C, Symons KT, Nguyen PM, Sablad M, Rozenkrants N, Zhang Y, Wang L, Yazdani N, Shiau AK, Noble SA, Rix P, Rao TS, Hassig CA, Smith ND. Discovery of dual inducible/neuronal nitric oxide synthase (iNOS/nNOS) inhibitor development candidate 4-((2-cyclobutyl-1H-imidazo[4,5-b]pyrazin-1yl)methyl)-7,8-difluoroquinolin$2(1 \mathrm{H})$-one (KD7332) part 2: identification of a novel, potent, and selective series of benzimidazole-quinolinone iNOS/nNOS dimerization inhibitors that are orally active in pain models. Journal of Medicinal Chemistry. 2010;53:7739-7755. DOI: 10.1021/jm100828n

[36] Cara LCL, Camacho ME, Carrión MD, Tapias V, Gallo MA, Escames G, Acuña-Castroviejo D, Espinosa A, Entrena A. Phenylpyrrole derivatives as neuronal and inducible nitric oxide synthase (nNOS and iNOS) inhibitors. European Journal of Medicinal Chemistry. 2009;44:2655-2666. DOI: 10.1016/j.ejmech.2008.11.013

[37] Nieto CI, Cabildo MP, Cornago MP, Sanz D, Claramunt RM, Torralba MC, Torres MR, Elguero J, García JA, López A, Acuña-Castroviejo D. Fluorination effects on NOS inhibitory activity of pyrazoles related to curcumin. Molecules. 2015;20:15643-15665. DOI: 10.3390/molecules200915643 
[38] Chayah M, Carrión MD, Gallo MA, Jiménez R, Duarte J, Camacho ME. Development of urea and thiourea kynurenamine derivatives: synthesis, molecular modeling, and biological evaluation as nitric oxide synthase inhibitors. ChemMedChem. 2015;10:874-882. DOI: $10.1002 / \mathrm{cmdc} .201500007$

[39] Li W, Zheng S, Higgins M, Morra Jr RP, Mendis AT, Chien CW, Ojima I, Mierke DF, DinkovaKostova AT, Honda T. New monocyclic, bicyclic, and tricyclic ethynylcyanodienones as activators of the Keap1/Nrf2/ARE pathway and inhibitors of inducible nitric oxide synthase. Journal of Medicinal Chemistry. 2015;58:4738-4748. DOI: 10.1021/acs.jmedchem.5b00393

[40] Tang W, Li H, Poulos TL, Silverman RB. Mechanistic studies of inactivation of inducible nitric oxide synthase by amidines. Biochemistry. 2015;54:2530-2538. DOI: 10.1021/acs. biochem.5b00135

[41] Yin GP, Li LC, Zhang QZ, An YW, Zhu JJ, Wang ZM, Chou GX, Wang ZT. iNOS inhibitory activity of sesquiterpenoids and a monoterpenoid from the rhizomes of Curcuma wenyujin. Journal of Natural Products. 2014;77:2161-2169. DOI: 10.1021/np400984c

[42] Lee J, Kim H, Lee TG, Yang I, Won DH, Choi H, Nam SJ, Kang H. Anmindenols A and B, inducible nitric oxide synthase inhibitors from a marine-derived Streptomyces sp. Journal of Natural Products. 2014;77:1528-1531. DOI: 10.1021/np500285a

[43] Brozíckova C, Mikulecka A, Otáhal J. Effect of 7-nitroindazole, a neuronal nitric oxide synthase inhibitor, on behavior and physiological parameters. Physiological Research. 2014;63:637-648.

[44] Banach M, Piskorska B, Czuczwar SJ, Borowicz KK, Nitric oxide, epileptic seizures, and action of antiepileptic drugs. CNS Neurological Disorders Drug Discovery. 2011;10:808-819. DOI: $10.2174 / 187152711798072347$.

[45] Entrena A, Camacho E, Carrión D, López-Cara LC, Velasco G, León J, Escames G, Acuña-Castroviejo D, Tapias V, Gallo MA, Vivo A, Espinosa A. Kynurenamines as neural nitric oxide synthase inhibitors. Journal of Medicinal Chemistry. 2005;48:8174-8181. DOI: $10.1021 / j m 050740$ o

[46] Maccallini C, Patruno A, Lannutti F, Ammazzalorso A, Filippis BD, Fantacuzzi M, Franceschelli S, Giampietro L, Masella S, Felaco M, Re N, Amoroso R. N-substituted acetamidine and 2-methylimidazole derivates as selective inhibitors of neuronal nitric oxide synthase. Bioorganic and Medicinal Chemistry Letters. 2010;20:6495-6499. DOI: 10.1016/j.bmcl.2010.09.059

[47] Delker SL, Ji H, Li H, Jamal J, Fang J, Xue F, Silverman RB, Poulos TL. Unexpected binding modes of nitric oxide synthase inhibitors effective in the prevention of cerebral palsy phenotype in an animal model. Journal of the American Chemical Society. 2010;132:5437-5442. DOI: 10.1021/ja910228a

[48] Lawton GR, Ranaivo HR, Wing LK, Ji H, Xue F, Martesek P, Roman LJ, Watterson $\mathrm{DM}$, Silverman RB. Analogues of 2-aminopyridine-based selective inhibitors of neuronal nitric oxide synthase with increased bioavailability. Bioorganic and Medicinal Chemistry. 2009;17:2371-2380. DOI: 10.1016/j.bmc.2009.02.017 
[49] Silverman RB, Lawton GR, Ranaivo HR, Chico LK, Seo J, Watterson DM. Effect of potential amine prodrugs of selective neuronal nitric oxide synthase inhibitors on blood-brain barrier penetration. Bioorganic and Medicinal Chemistry. 2009;17:7593-7605. DOI: 10.1016/j.bmc.2009.08.065

[50] Xue F, Fang J, Lewis WW, Martásek P, Roman LJ, Silverman RB. Potent and selective neuronal nitric oxide synthase inhibitors with improved cellular permeability. Bioorganic and Medicinal Chemistry Letters. 2010;20:554-557. DOI: 10.1016/j. bmcl.2009.11.086

[51] Carrión D, Chayah M, Entrena A, López A, Gallo MA, Acuña-Castroviejo D, Camacho ME. Synthesis and biological evaluation of 4,5-dihydro- $1 \mathrm{H}$-pyrazole derivatives as potential nNOS/iNOS selective inhibitors. Part 2: influence of diverse substituents in both the phenyl moiety and the acyl group. Bioorganic and Medicinal Chemistry. 2013;21:4132-4142. DOI: 10.1016/j.bmc.2013.05.016

[52] Cinelli MA, Li H, Chreifi G, Martásek P, Roman LJ, Poulos TL, Silverman RB. Simplified 2-aminoquinoline-based scaffold for potent and selective neuronal nitric oxide synthase inhibition. Journal of Medicinal Chemistry. 2014;57:1513-1530. DOI: 10.1021/ jm401838x

[53] Cinelli MA, Li H, Pensa AV, Kang S, Roman LJ, Martásek P, Poulos TL, Silverman RB. Phenyl ether- and aniline-containing 2-aminoquinolines as potent and selective inhibitors of neuronal nitric oxide synthase. Journal of Medicinal Chemistry. 2015;58:8694-8712. DOI: 10.1021/acs.jmedchem.5b01330

[54] Mukherjee P, Li H, Sevrioukova I, Chreifi G, Martásek P, Roman LJ, Poulos TL, Silverman RB. Novel 2,4-disubstituted pyrimidines as potent, selective, and cell-permeable inhibitors of neuronal nitric oxide synthase. Journal of Medicinal Chemistry. 2015;58:10671088. DOI: $10.1021 / j m 501719 \mathrm{e}$

[55] Li H, Wang HY, Kang S, Silverman RB, Poulos TL. Electrostatic control of isoform selective inhibitor binding in nitric oxide synthase. Biochemistry. 2016;55:3702-3707. DOI: 10.1021/acs.biochem.6b00261

[56] Kang S, Li H, Tang W, Martasek P, Roman LJ, Poulos TL, Silverman RB. 2-aminopyridines with a truncated side chain to improve human neuronal nitric oxide synthase inhibitory potency and selectivity. Journal of Medicinal Chemistry. 2015;58:5548-5560. DOI: 10.1021/acs.jmedchem.5b00573

[57] Wang HY, Qin Y, Li H, Roman LJ, Martasek P, Poulos TL, Silverman RB. Potent and selective human neuronal nitric oxide synthase inhibition by optimization of the 2-aminopyridine-based scaffold with a pyridine linker. Journal of Medicinal Chemistry. 2016;59:4913-4925. DOI: 10.1021/acs.jmedchem.6b00273

[58] Xu G, Chen Y, Shen K, Wang X, Li F, He Y. The discovery of potentially selective human neuronal nitric oxide synthase (nNOS) inhibitors: a combination of pharmacophore modelling, CoMFA, virtual screening and molecular docking studies. International Journal of Molecular Sciences. 2014;15:8553-8569. DOI: 10.3390/ijms15058553 
[59] Xue F, Fang J, Delker SL, Li H, Martasek P, Roman LJ, Poulos TL, Silverman RB. Symmetric double-headed aminopyridines, a novel strategy for potent and membranepermeable inhibitors of neuronal nitric oxide synthase. Journal of Medicinal Chemistry. 2011;54:2039-2048. DOI: 10.1021/jm101071n

[60] Delker SL, Xue F, Li H, Jamal J, Silverman RB, Poulos TL. Role of zinc in isoform-selective inhibitor binding to neuronal nitric oxide synthase. Biochemistry. 2010;49:10803-10810. DOI: $10.1021 /$ bi1013479

[61] Huang H, Li H, Martásek P, Roman LJ, Poulos TL, Silverman RB. Structure-guided design of selective inhibitors of neuronal nitric oxide synthase. Journal of Medicinal Chemistry. 2013;56:3024-3032. DOI: 10.1021/jm4000984

[62] Jing Q, Li H, Chreifi G, Roman LJ, Martásek P, Poulos TL, Silverman RB. Chiral linkers to improve selectivity of double-headed neuronal nitric oxide synthase inhibitors. Bioorganic and Medicinal Chemistry Letters. 2013;23:5674-5679. DOI: 10.1016/j. bmcl.2013.08.034

[63] Jing Q, Li H, Roman LJ, Martásek P, Poulos TL, Silverman RB. Accessible chiral linker to enhance potency and selectivity of neuronal nitric oxide synthase inhibitors. ACS Medicinal Chemistry Letters. 2014;5:56-60. DOI: 10.1021/ml400381s

[64] Kang S, Tang W, Li H, Chreifi G, Martásek P, Roman LJ, Poulos TL, Silverman RB. Nitric oxide synthase inhibitors that interact with both heme propionate and tetrahydrobiopterin show high isoform selectivity. Journal of Medicinal Chemistry. 2014;57:4382-4396. DOI: $10.1021 /$ jm5004182

[65] Huang H, Li H, Yang S, Chreifi G, Martásek P, Roman LJ, Meyskens FL, Poulos TL, Silverman RB. Potent and selective double-headed thiophene-2-carboximidamide inhibitors of neuronal nitric oxide synthase for the treatment of melanoma. Journal of Medicinal Chemistry. 2014;57;686-700. DOI: 10.1021/jm401252e

[66] Gusarov I, Shatalin K, Starodubtseva M, Nudler E. Endogenous nitric oxide protects bacteria against a wide spectrum of antibiotics. Science. 2009;325:1380-1384. DOI: 10.1126/ science.1175439.

[67] Holden JK, Li H, Jing Q, Kang S, Richo J, Silverman RB, Poulos TL. Structural and biological studies on bacterial nitric oxide synthase inhibitors. Proceedings of the National Academy of Sciences of the United States of America. 2013;110:18127-12131. DOI: 10.1073/pnas.1314080110

[68] Holden JK, Kang S, Hollingsworth SA, Li H, Lim N, Chen S, Huang H, Xue F, Tang $\mathrm{W}$, Silverman RB, Poulos TL. Structure-based design of bacterial nitric oxide synthase inhibitors. Journal of Medicinal Chemistry. 2015;58: 994-1004. DOI: 10.1021/jm501723p

[69] Holden JK, Dejam D, Lewis MC, Huang H, Kang S, Jing Q, Xue F, Silverman RB, Poulos TL. Inhibitor bound crystal structures of bacterial nitric oxide synthase. Biochemistry. 2015;54:4075-4082. DOI: 10.1021/acs.biochem.5b00431. 
[70] Alexander JH, Reynolds HR, Stebbins AL, Dzavik V, Harrington RA, Van der Werf F, Hechman JS.Effect of tilarginine acetate in patients with acute myocardial infarction and cardiogenic shock: the TRIUMPH randomized controlled trial. Journal of American Medical Association. 2007;297:1657-1666.

[71] Wong VW, Lerner E. Nitric oxide inhibition strategies. Future Sciences OA. 2015;1:piiFSO35. DOI: 10.4155/FSO.15.35

[72] Dzavik V, Cotter G, Reynolds HR, Alexander JH, Ramanathan K, Stebbis AL, Hathaway D, Farkouh ME, Ohman EM, Baran DA, Prondzinsky R, Panza JA, Cantor WJ, Vered Z, Buller CE, Kleiman NS, Webb JG, Holmes DR, Parrillo JE, Hazen SL, Gross SS, Harrington RA, Hachman JS. Effect of nitric oxide synthase inhibition on haemodynamics and outcome of patients with persistent cardiogenic shock complicating acute myocardial infarction: a phase II dose-ranging study. European Heart Journal. 2007;28:1109-1116. DOI: 10.1093/eurheartj/ehm075.

[73] Cottera G, Kaluskia E, Miloa O, Blatta A, Salaha A, Hendlera A, Krakovera R, Golickb A, Vereda Z. LINCS: L-NAME (a NO synthase inhibitor) in the treatment of refractory cardiogenic shock: a prospective randomized study. European Heart Journal. 2003;24:1287-1295. DOI: 10.1016/S0195-668X(03)00193-3.

[74] Salem R, Mebazaa A. Nitric oxide inhibition rapidly increases blood pressure with no change in outcome in cardiogenic shock: the TRIUMPH trial. Critical Care. 2007;11;1-2. DOI: $10.1186 /$ cc5925.

[75] Luke JJ, LoRusso P, Shapiro GI, Krivoshik A, Schuster R, Yamazaki T, Arai Y, Fakhoury A, Dmuchowski C, Infante JR. ASP9853, an inhibitor of inducible nitric oxide synthase dimerization, in combination with docetaxel: preclinical investigation and a Phase I study in advanced solid tumors. Cancer Chemotherapy Pharmacology. 2016;77:549-558. DOI: 10.1007/s00280-016-2967-0. 
